\title{
Comparative analysis of results of the pedagogical experiment on creative imagination development in speech impaired preschool children
}

\author{
Ekaterina Novikova ${ }^{1, *}$ \\ ${ }^{1}$ Nizhnevartovsk State University, 56 Lenin st., 628605, Nizhnevartovsk Russia
}

\begin{abstract}
The relevance of the research is due to the fact that one of the most important mental processes in preschool children is creative imagination. Thanks to creative imagination, the child can find new ways to solve arising problems. The article reflects results of the ascertaining and control experiments and presents statistical data.
\end{abstract}

\section{Introduction}

Constant changes as a result of socio-economic transformations require the development of a creative individual who can unconventionally and effectively solve new problems. Particular attention to the system of modern education is due to the fact that education is the basis for solving socio-economic problems, preserving and developing science and culture [1].Current laws regulating activities of a teacher (Professional Standards, Federal State Educational Standards, etc.)systematize and apply requirements of a changing world to professional activities of a teacher to ensure selfpersistent, creative, and productive activities of students [2]. The Federal State Educational Standard for Preschool Education (the Federal State Educational Standard) is aimed at creating favorable conditions for the development of children in accordance with their age-specific individual features abilities and creative potential. Inclusive education is aimed at creating variable forms of education for children with disabilities.

Inclusive education shows that main activities of the preschool education are to include children with disabilities in a team of peers and adults as equal partners. In this case, the teacher tries to find various types of communication that will be interesting and accessible to each member of the group. Indeed, the significance of creative activities and its support involves development of the "I", reduction of the inferiority complex and negative perception of the world in psychological and pedagogical literature and educational practice [3].

A central aspect in preparing preschool teachers for inclusive education is familiarity with developmental features of children with disabilities, co-educational technologies, and principles of developing adapted basic educational programs for people with different characteristics of health [4]. The methods used by the teacher are determined by basic structures of his professionalism: a value-motivational component, a position in relation to himself and a child as a model implemented in communication, training and assessment of performance [5].

The problem of developing creative imagination is manifested in objective contradictions: the state policy requires development of a creative personality, but conditions for developing creativity are insufficient, there is no support for centers for gifted children; The Federal Preschool Education Standard (FPES) puts forward requirements for the development of child's creativity, but in most recommended educational programs, tasks are set to develop only cognitive processes; Psychological and pedagogical science and practice justify and implement innovative technologies for the development of creative imagination of preschoolers. At the same time, at the level of specific educational organizations, attention is paid to traditional drawing techniques. These contradictions made it possible to formulate the initial problem of determining and analyzing psychological and pedagogical resources for developing creative imagination of senior preschoolers with speech impairment using nontraditional drawing techniques.

In this regard, all preschool educational organizations solve an important task of developing the creative potential of the younger generation which requires improvement of the educational process, taking into account psychological laws of the entire system of the cognitive process.

\section{Methods}

The problem of development of creative imagination does not remain without attention in psychological and pedagogical science, because imagination is an integral component of any form of creative activities of a child. In this regard, the important task of developing the creative potential of the younger generation has been solved by psychologists and teachers. The studies by E.I. Ignatiev, S.L. Rubinstein, L.S. Vygotsky, D.B. Elkonina,

* Corresponding author: ekaterina94novikova@yandex.ru 
V.A. Krutetskogo, N.S. Leites, J.P. Ponomoreva, V.V. Davydova, O.M. Dyachenko, G.A. Uruntaeva, E.E. Kravtsov show that an integral component of any form of creative activities is imagination. Imagination is a prerequisite for the effective acquisition of new knowledge and a condition for the creative transformation of children's skills. It contributes to the self-development, determines the effectiveness of the educational process [5].

Undoubtedly, the study of creative imagination in speech impaired children is of particular interest, since the emerging originality in speech development creates difficulties in the development of cognitive processes. Speech impaired children find it difficult to master word meanings, which, of course, affects the level of development of creative imagination.

In the correctional-pedagogical system of education and training of speech impaired children, an important role belongs to productive activities. Therefore, great opportunities for the development of creative imagination of speech impaired children are represented by visual activities. Nevertheless, the use of innovative technologies, including non-traditional drawing techniques to solve this problem changes the development of creativity. For example, there is research proving that unconventional drawing techniques create a psychophysical basis for speech development. The relationship between imagination and thinking determines what has toto be done and how to do it. Thinking and imagination arise in a problem situation. Their basis is anticipatory reflection of reality, carried out in the process of imagination which occurs in the form of vivid representations, while the anticipatory reflection in thinking processes occurs through the use of concepts used to know the environment. Considering imagination as one of the most important, interesting and mysterious properties of the human mind determines a constant interest in this phenomenon from psychological and pedagogical points of view. The process of creative imagination is studied in psychology of artistic creativity by S.K. Langerom, O.I. Nikiforova, S.Kh. Rapport, B.M. Runin, M.S. Arnaudov, A.I. Klimovitsky, M.E. Tarakanov, V.A. Drankov and others [6]. Famous psychologists and educators of the twentieth century made a significant contribution to the comprehensive development of science: (Z. Freud, J. Piaget, T. Ribot, L.S. Vygotsky, S.L. Rubeishtein, A.V. Petrovsky, M.G. Yaroshevsky and etc). Modern researchers expanded the content of the concept of imagination. Imagination is defined as a process in accordance with the needs of the individual; an ability to represent (education, retention and arbitrary reproduction) the image of an object in accordance with the object itself, existing either in reality or in its representation [5].

\section{Types of non-traditional drawing techniques used bysenior preschool children}

The use of non-traditional techniques is determined by age characteristics of preschool children, allows us to diversify a child's ability to draw, attracts attention to the study of visual possibilities, materials, visual art in general.

According to V.D. Shadrikova, the term "nontraditional" means the use of new materials, tools, drawing methods that are not generally used in the teaching practice. In preschool educational institutions, teachers use non-traditional drawing techniques in visual activities [7]. The use of non-traditional drawing techniques enriches children's knowledge and ideas about objects, materials, their properties and methods of application. Children are taught to draw with soap, candles or glue. Children try to draw with their palms, fingers, fists, palm edges, use threads, rope and natural materials (tree leaves).

Preschoolers mix paints with soap foam and glue. They use gouache paints or water-paints [8].

According to I.A. Lykova, unconventional drawing techniques give impetus to the development of creative imagination, manifestation of independence, initiative, expression of individuality, developcreative abilities. By applying and combining different drawing methods, children learn to think and decide what techniques they will use to express the image. They analyze their results, compare them with other works, learn to express their points of view. Children have a desire to make their drawings more interesting, accurate and unusual [9].

Many teachers note that non-traditional drawing techniques eliminate fears; develop self-confidence, spatial thinking, imagination, motor skills and tactile perception, rhythm, attention, perseverance, color perception, an ability to work with various materials; encourage children to find creative solutions; children receive aesthetic pleasure, develop control and selfcontrol skills [10].

Let us consider some types of non-traditional drawing techniques used in preschool institutions:

"Leaves on paper": This non-traditional technique is used when working with senior preschoolers. The main means of expressiveness isa color and a texture, the following materials can be used: paper, gouache, brushes, tree leaves. Leaves are painted with gouache.

"Drawing on wet paper". This non-traditional technique is used when working with senior preschoolers. The main means of expressiveness are a stain, a color and a line. Aspen materials, a thick sheet of paper, watercolor crayons, a sponge, water in a saucer, brushes are used. The sheet of paper is wetted and placed on a damp cloth. The child can start painting. Paint should spread a little.

"Conventional blotography and tube blotography". This non-traditional technique is used when working with senior preschoolers. The most important means of expressiveness is a stain. Aspen materials, paper, mascara or liquid diluted gouache in a bowl, a plastic spoon, a tube, a thread of medium thickness are used.

"Black and White Scratching and Color Scratching".Five-year old children begin to get acquainted with these unconventional drawing techniques. The main means of expression area line, a stroke, a contrast and a color. The following materials are used: a half-card or thin white sheet of paper, a candle, a wide brush, black mascara, liquid soap (about 
one drop per tablespoon of mascara) or tooth powder, bowls, a stick with sharpened ends; for color scratching, a colored cardboard or a thick sheet of paper, previously painted with watercolors or felt-tip pens, a candle, a wide brush, bowls for gouache, a stick with sharpened ends are used. The method of obtaining the image is as follows: the child rubs the sheet with a candle so that it is completely covered with a layer of wax. Then, mascara with liquid soap or tooth powder is applied; it is poured with mascara without additives. After drying, the pattern is scratched with a stick.

"Spraying."This non-traditional technique is used when working with senior preschoolers. The means of expressiveness are a point and a texture. Materials: paper, gouache, a hard brush, a piece of thick cardboard or plastic $(5 \times 5 \mathrm{~cm})$. This technique is characterized by the following method: the child takes paint on the brush and strikes the cardboard with a brush that holds above the paper. Paint is sprayed onto paper.

"Monotype and landscape monotype ". This nontraditional technique is used when working with senior preschoolers. The main means of expressiveness are a stain, a tone, a vertical symmetry, an image of space, a color, a symmetry. The following materials are used: a sheet of paper, brushes, gouache or watercolor, a wet sponge. The method is as follows: an image on cellophane is transferred onto paper. The child paints with a brush, a cotton swab, or a finger. The paint should be thick and bright. Until the paint has dried, the cellophane is faced down on a thick white sheet of paper. The painting gets wet and lifted up. The child has two drawings. The image remains on the cellophane or on the paper. The child bends a sheet of paper and draws two spots, for example, butterfly wings. The child bends the sheet along the intended line and draws a palm over it. Then the child opens and analyzes what happened.

When using non-traditional drawing techniques in working with preschool children, they do not get tired so quickly and maintain their performance throughout the entire working day. Unconventional drawing techniques enable the teacher to implement an individual approach to each child, taking into account his desires and interest. In addition, the use of non-traditional drawing techniques creates opportunities for the intellectual development of a child and correction.

\section{Results}

The control experiment was carried out using the following diagnostic tools: the method by T.S. Komarova "Finish drawing of circles", the method by T.D.Martsinskovskaya "Draw something", the method determining the level of development of creative abilities by N.V. Shaidurova.

Let us deal with the quantitative and qualitative analysis of the results of the control experiment. At the first stage of the control experiment, peculiarities of the development of creative imagination of senior preschool children with speech impairment (T.S.Komarova'smethod) were determined, the data are presented in Table 1.
Table 1. Change in the level of development of creative imagination of senior preschoolers using T.S.Komarova's method "Finish drawing of circles"

\begin{tabular}{|l|c|c|c|c|}
\hline \multirow{2}{*}{ Level } & \multicolumn{2}{|c|}{$\begin{array}{c}\text { Ascertaining } \\
\text { experiment }\end{array}$} & \multicolumn{2}{c|}{ Control experiment } \\
\cline { 2 - 5 } & Number & $\%$ & $\begin{array}{c}\text { Numb } \\
\text { er }\end{array}$ & $\%$ \\
\hline High & 0 & 0 & 3 & 28 \\
\hline Medium & 3 & 28 & 4 & 36 \\
\hline Low & 8 & 72 & 4 & 36 \\
\hline
\end{tabular}

A comparative analysis of the results presented in Table 1, allows us to draw the following conclusions:

- 4 senior preschool children with speech impairment $(36 \%)$ were included in groups with a low level of development of creative imagination according to the criteria of originality; quantitative features; accuracy; productivity (the result increased by $36 \%$ );

- 4 senior preschoolers $(36 \%)$ showed an average level of development of creative imagination (the result increased by $8 \%$ );

- 3 senior preschool children with speech impairment $(28 \%)$ showed a high level of development of creative imagination; the result increased by $28 \%$.

Table 2. Change in the level of development of creative imagination of senior preschoolers using

T.D.Martsinkovskaya's method "Draw Something"

\begin{tabular}{|l|c|c|c|c|}
\hline \multirow{2}{*}{ Level } & \multicolumn{2}{|c|}{$\begin{array}{c}\text { Ascertaining } \\
\text { experiment }\end{array}$} & \multicolumn{2}{c|}{ Control experiment } \\
\cline { 2 - 5 } & Number & $\%$ & $\begin{array}{c}\text { Numb } \\
\text { er }\end{array}$ & $\%$ \\
\hline High & 0 & 0 & 3 & 28 \\
\hline Medium & 3 & 28 & 8 & 72 \\
\hline Low & 8 & 72 & 0 & 0 \\
\hline
\end{tabular}

A comparative analysis of the results presented in Table 2, allows us to draw the following conclusions:

- 8 respondents $(72 \%)$ were included in the group with an average level of development of creative imagination according to the criteria of independence of design and careful study of details; the result increased by $45 \%$;

- 3 respondents $(28 \%)$ showed a high level of development of creative imagination; children with a high level were absent in the ascertaining experiment;

- Respondents with a low level of development of creative imagination were not identified.

Table 3. Change in the level of development of creative imagination of senior preschoolers using N.V. Shaidurova's method

\begin{tabular}{|l|c|c|c|c|}
\hline \multirow{2}{*}{ Level } & \multicolumn{2}{|c|}{$\begin{array}{c}\text { Ascertaining } \\
\text { experiment }\end{array}$} & \multicolumn{2}{c|}{ Control experiment } \\
\cline { 2 - 5 } & $\begin{array}{c}\text { Numb } \\
\text { er }\end{array}$ & $\%$ & $\begin{array}{c}\mathrm{Nu} \\
\mathrm{mb} \\
\mathrm{er}\end{array}$ & $\%$ \\
\hline High & 0 & 0 & 4 & 36 \\
\hline Medium & 4 & 36 & 3 & 27 \\
\hline Low & 7 & 64 & 4 & 36 \\
\hline
\end{tabular}

A comparative analysis of the results presented in Table 3, allows us to draw the following conclusions: 
- 4 respondents $(36 \%)$ were included in groups with a low level of development of creative imagination according to the criterion spatial position on a sheet of paper; the result increased by $28 \%$ due to the fact that there are four respondents with a high level;

- 3 senior preschoolers with speech impairment (27\%) showed an average level of development of creative imagination due to an increase in 2 respondents with an average level of development;

- 4 senior preschool children with speech impairment (36\%) showed a high level of development of creative imagination during the ascertaining experiment.

Comparative results of the ascertaining and control experiments showed that for each criterion and for each technique, the level of development of creative imagination of senior preschoolers with speech impairment increased. Generalization and analysis of these results as qualitative and quantitative characteristics provided a basis for assessing the level of development of creative imagination insenior preschoolers with speech impairment.

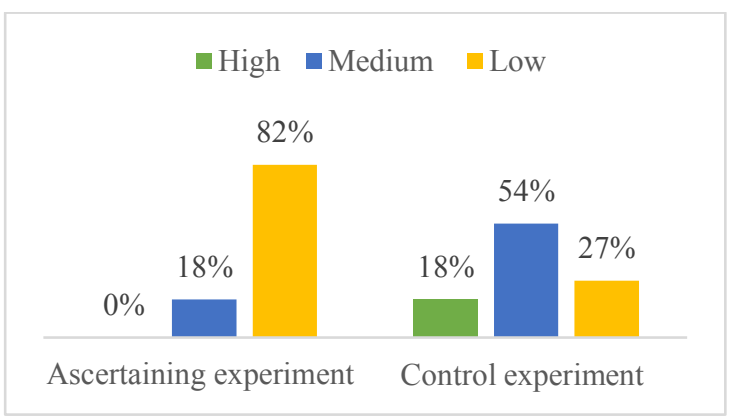

Fig 1. A comparative diagram of the results of the ascertaining and control experiments on the development of creative imagination in senior preschool children with speech impairment

The diagram shows that at the control stage, the number of children with a low level of creative imagination decreased from $82 \%$ (9 children) to $27 \%$ (3 children). After the control experiment, the number of children with a high level of creative imagination was $18 \%$, and with an average level of creative imagination from $18 \%$ ( 3 children) to $54 \%$ ( 6 children).

To establish the significance of the results, the Student t-test was used, because the requirements are correlated with the results obtained, namely: the data are quantitative, the number of respondents is 22 , the study involved two connected samples.

To compare the sample, the Student t-test was used. This criterion is calculated by the following formula:

$$
t=\frac{\left|x_{1}-x_{2}\right|}{\sqrt{m_{1}^{2}+m_{2}^{2}}},
$$

where $x_{1}$ and $x_{2}$ are arithmetic mean in samples 1 and 2, $m_{1}$ and $m_{2}-$ For the sample consisting of 11 people, this criterion is quite effective.

The calculation of significance $(t)$ is carried out according to the results obtained by the results of each methodology, as well as by points based on each methodology. $t_{1}$ - results by T.S. Komarova's method "Finish drawing of circles",

$t_{2}$ - results by T.D. Martsinkovskaya's method "Draw something",

$t_{3}-$ results by N.V. Shaidurova's method

$t_{t}$ - results by total points based on all the methods.

$$
\begin{gathered}
t_{1}=\frac{\left|1,6_{1}-2,1_{2}\right|}{\sqrt{0,07_{1}^{2}+0,2_{2}^{2}}}=\frac{0,5}{0,2}=2,5 \\
t_{2}=\frac{\left|1,7_{1}-2,4_{2}\right|}{\sqrt{0,07_{1}^{2}+0,13_{2}^{2}}}=\frac{0,7}{0,2}=3,5 \\
t_{3}=\frac{\left|1,3_{1}-2_{2}\right|}{\sqrt{0,1_{1}^{2}+0,3_{2}^{2}}}=\frac{0,7}{0,3}=2,5 \\
t_{t}=\frac{\left|1,5_{1}-2,1_{2}\right|}{\sqrt{0,1_{1}^{2}+0,2_{2}^{2}}}=\frac{0,6}{0,2}=3
\end{gathered}
$$

After having calculated $t$, it was compared with the table value at a group of freedom degrees $d f_{1}=n_{1}+$ $n_{2}-2$,for the first group $n_{1}=11, n_{1}=11, d f=11+$ $11-2=20$

Hypotheses $\mathrm{H}_{1}$ and $\mathrm{H}_{0}$ were formulated. If the computational value is equal to or exceeds the critical $\mathrm{t}_{0.05}$, hypothesis $\mathrm{H}_{1}$ is accepted - changes occurred after the implementation of psychological and pedagogical measures at the ascertaining stage of the experiment. They were aimed at developing creative imagination of senior preschoolers with speech impairment on the basis of "partnerships" of parents, teachers and peers. Ifthecomputationalvalueislessthancritical, hypothesis $\mathrm{H}_{0}$ is accepted: changesarearesultofthe ascertaining experiment.

The arithmetic mean and errors, as well as the significance level are presented in Table 4.

Table 4.Calculation of t-Student's criterion

\begin{tabular}{|c|c|c|c|}
\hline Methods & $\begin{array}{c}\text { Ascertain } \\
\text { ing } \\
\text { stage }\end{array}$ & $\begin{array}{c}\text { Control } \\
\text { stage }\end{array}$ & $\begin{array}{c}\text { Significanceofdif } \\
\text { ferences }\end{array}$ \\
\hline $\begin{array}{c}\text { T.S. } \\
\text { Komarova's } \\
\text { method }\end{array}$ & $1,6 \pm 0,07$ & $2,1 \pm 0,2$ & $\mathrm{p}=0,05$ \\
\hline $\begin{array}{c}\text { T.D. } \\
\text { Marcinkovs } \\
\text { kaya's } \\
\text { method }\end{array}$ & $1,7 \pm 0,07$ & $2,4 \pm 0,13$ & $\mathrm{p}=0,01$ \\
\hline $\begin{array}{c}\text { N.V. } \\
\text { Shaidurova' } \\
\text { s method }\end{array}$ & $1,3 \pm 0,1$ & $2 \pm 0,3$ & $\mathrm{p}=0,05$ \\
\hline Total & $1,5 \pm 0,1$ & $2,1 \pm 0,2$ & $\mathrm{p}=0,01$ \\
\hline
\end{tabular}

As can be seen from Table 4, the relationship between the dependence of the indicators before and after the experiment is statistically significant with a reliability of $95 \%(\mathrm{p}=0.05)$ and $99 \%(\mathrm{p}=0.01)$. The computational value is equal to or larger than the critical value, that is, it is necessary to accept hypothesis $\mathrm{H}_{1}$ (changes identified after the ascertaining experiment did not occur by chance).

Thus, hypothesis $\mathrm{H}_{0}$, according to which the changes after the formativeexperiment occurred by chanceis rejected, and hypothesis $\mathrm{H}_{1}$ (the changes after the implementation of psychological and pedagogical measures during the formativeexperiment did not occur 
by chance) is accepted (i.e. the values after the formativeexperiment are higher than after the ascertaining one). Consequently, the $t$-Student's criterion indicates that a positive shift in the estimates is significant, i.e. there is a positive dynamics in the development of creative imagination of senior preschoolers with speech impairment.

\section{Conclusion}

The control experiment made it possible to ascertain positive changes that occurred during the formative experiment, which helps increase the level of development of creative imagination of senior preschoolers with speech impairment using nontraditional drawing techniques. The number of children exhibiting a low level of creative imagination decreased, the number of children with high and medium levels increased. The control experiment showed that after the implementation of psychological and pedagogical measures, there are positive changes in qualitative characteristics of creative imagination of senior preschool children.

To establish the significance of the results, we used the t-Student criterion. Based on the results obtained, it can be argued that indicators were improved: there has been a positive trend in the development of creative imagination of senior preschoolers with speech impairment using non-traditional drawing techniques.

Thus, the level of creative imagination of senior preschoolers depends on the professional competence of teachers;teachers should possess required skills to organize creative activities [9], involve parents in the educational process.

\section{References}

1. L.A. Ibragimova, G.A. Petrova., M.P. Trofimenko Bulletin of the Nizhnevartovsk State Humanitarian University. Competence-based approach- methodological basis of modern education,№1, 5766(2010)

2. L. Ibragimova, I. Skobeleva Conditions for creation and development of media culture in students of secondary professional education, Mediaeducation. №1, 89-94.(2018)

3. E.A. Novikova. XX All-Russian Student Scientific and Practical Conference of Nizhnevartovsk State University. Features of the development of creative imagination of senior preschool children with speech impairment, 381-385 (2018)

4. T.V. Safonova, A.S. Suntsova., R.G. Aslaeva Integration of education. A study of orientation to a personal model of interaction with children as a structural component of teachers' readiness for inclusive education, Vol. 23, №1, 50-65 (2019)

5. T.V. Snegireva., E.A. Novikova XXI International scientific-practical conference World Science: Problems and innovations Theoretical aspects of the problem of creative imagination in scientific knowledge, 145-150 (2018)

6. G.V. Doronin. Imagination as a way of creative counseling of imaginative reality. Thesis. Saratov, 57 (2005)

7. G.D. Kirillova. Initial forms of creative imagination in children. Preschooleducation, № 2, 41-46 (1971)

8. T.S. Komarova. Children in the world of creativity.Moscow, 190 (1995)

9. L.A. Ibragimova., I.E. Skobeleva Bulletin of Nizhnevartovsk State University. Electronic educational resources as an important element in ensuring the quality training of future mid-level specialists, №3, 16-20 (2017)

10. S.G. Korolyova. Volgograd Development of creative abilities of 5-7-year old children: diagnostics, system of classes(2010) 